\title{
Microstructure and Complex Permeability Spectra of Polycrystalline Cu-Zn Ferrites
}

\author{
Shahida Akhter ${ }^{1 *}$, D. P. Paul ${ }^{1}$, M. A. Hakim², S. Akhter ${ }^{2}$, D. K. Saha ${ }^{2}$, B. Anjuman ${ }^{2}$, and \\ F. Islam ${ }^{3}$ \\ ${ }^{1}$ Department of Physics, University of Chittagong, Chittagong-4331, Bangladesh \\ ${ }^{2}$ Materials Science Division, Atomic Energy Centre, Dhaka-1000, Bangladesh \\ ${ }^{3}$ Department of Glass and Ceramic Engineering, Bangladesh University of Engineering and \\ Technology, Dhaka, Bangladesh
}

Received 29 May 2012, accepted in final revised form 1 August 2012

\begin{abstract}
$\mathrm{Cu}-\mathrm{Zn}$ ferrites of composition $\mathrm{Cu}_{1-\mathrm{x}} \mathrm{Zn}_{\mathrm{x}} \mathrm{Fe}_{2} \mathrm{O}_{4}$ were prepared by double sintering ceramic technique at $950^{\circ} \mathrm{C}$ and $1050^{\circ} \mathrm{C}$ for 3 hours and 2 hours, respectively. Structural and magnetic properties of the $\mathrm{Cu}-\mathrm{Zn}$ ferrites were investigated by using X-ray diffraction, microstructure study and complex permeability behaviour. X-ray analysis indicated the formation of single-phase cubic spinel structure for all samples. The lattice parameter was found to increase with increasing Zn content obeying Vegard's law. The X-ray and bulk densities of the $\mathrm{Cu}-\mathrm{Zn}$ ferrite significantly decreased whereas porosity increased with increasing $\mathrm{Zn}$ concentration. Micrographs exhibited decrease in grain size with increasing concentrations. The real part $\mu^{\prime}$ of initial permeability remained constant up to certain lower range of frequency after which it decreased to lower value of permeability. $\mu^{\prime}$ increased with increasing Zn contents up to $x=0.5$, after that it decreased with higher Zn content but was also found to increase with sintering temperature. The possible reasons responsible for change in structural, microstructural and complex permeability with increasing of nonmagnetic $\mathrm{Zn}^{2+}$ ion are ascertained.
\end{abstract}

Keywords: Ferrites; Density; Porosity; Micrographs; Permeability.

(c) 2012 JSR Publications. ISSN: 2070-0237 (Print); 2070-0245 (Online). All rights reserved.

doi: http://dx.doi.org/10.3329/jsr.v4i3.10798 J. Sci. Res. 4 (3), 551-560 (2012)

\section{Introduction}

Ferrites have high potential for several electromagnetic devices in the radio frequency region, since they have frequency dependent physical property such as permeability. Especially, polycrystalline ferrite has been extensively used in many electronic devices because of its high permeability in the radio frequency region, high electrical resistivity, mechanical toughness and chemical stability [1]. Useful frequency range of ferrite is

* Corresponding author: shahida212@yahoo.com 
limited by the onset of resonance phenomenon for which either the permeability begins to fall at a critical frequency or the losses rise sharply. Hence the knowledge of the frequency dependence of the initial permeability and loss is necessary. Cu-ferrite and $\mathrm{Cu}-$ containing ferrites form an interesting group of ferrites because of their typical electrical and magnetic properties and change in crystal structure on thermal treatment [2]. Znsubstituted $\mathrm{Cu}$-ferrite have been commercially used for many years as high-frequency devices such as radio frequency coil, transformer cores, rod antenna etc. [3]. The microstructure study of ferrites can provide substantial information on various magnetic properties such as permeability. However, microstructures of ferrites are highly sensitive to preparation method, sintering condition, composition including impurities and dopants [4-6]. There are many experimental and theoretical investigations on the microstructure and frequency dispersion of complex permeability in polycrystalline ferrites [7-10]. The complex permeability spectra of polycrystalline ferrites depend not only on the chemical composition of the ferrite but also on the post-sintering density and the microstructure such as grain size and porosity. It was found that the sintering temperature has a great effect on the structural and magnetic properties of ferrites. In the present work, the influence of $\mathrm{Zn}$ substitute for $\mathrm{Cu}$ on the properties of $\mathrm{Cu}-\mathrm{Zn}$ ferrites has been investigated by studying $\mathrm{XRD}$, microstructure and frequency dependence of complex permeability.

\section{Experimental}

Ferrite samples of the chemical formula $\mathrm{Cu}_{1-\mathrm{x}} \mathrm{Zn}_{\mathrm{x}} \mathrm{Fe}_{2} \mathrm{O}_{4}(x=0.0,0.1,0.2,0.3,0.4$ 0.5, 0.6, 0.7) were prepared by the double sintering ceramic technique at Materials Science Division, Atomic Energy Centre, Dhaka, Bangladesh. High purity reagent nano-powders of $\mathrm{CuO}, \mathrm{ZnO}$, and $\mathrm{Fe}_{2} \mathrm{O}_{3}$ were mixed according to their molecular weight. Intimate mixing for the materials was carried out for 4 hours using agate mortar and then the materials in ethyl alcohol were poured into an agate jar placed into a planetary grinding miller, and then the materials were continuously milled for 4 hours with stainless steel balls of different sizes in diameter. The slurry was dried and was pressed into disc shape sample. The disc shaped sample was pre-sintered at $850^{\circ} \mathrm{C}$ for 6 hours at a heating rate of $4^{0} \mathrm{C} /$ minute in air to form ferrite through chemical reaction. The pre-sintered material was again crushed and wet milled for another 4 hours in distilled water to reduce it to small crystallites of uniform size. The mixture was dried and a few drops of saturated solution of polyvinyl alcohol were added as a binder. The resulting powders were pressed uniaxially under a pressure of $20 \mathrm{~Pa}$ and $15 \mathrm{~Pa}$ in a stainless steel dies to make pellets (9 mm diameter, $3 \mathrm{~mm}$ thickness) and toroids (12 mm outer diameter, $8 \mathrm{~mm}$ inner diameter and $4 \mathrm{~mm}$ thickness), respectively. The pressed pellets and toroids were then finally sintered at $950^{\circ} \mathrm{C}$ and $1050^{\circ} \mathrm{C}$ for 3 hours and 2 hours respectively in air and cooled in the furnace. All samples were heated slowly in the programmable Muffle furnace (Model HTL 10/17, Germany) at the rate of about $220 \%$ hour increase to avoid cracking of the samples. The surfaces of the all samples were polished in order to remove any oxide layer 
formed during the process of sintering. The weight and dimensions of the pellets were measured to determine bulk densities.

Phase analysis was done by X-ray diffraction using Phillips (PW3040) X' Pert PRO Xray diffractometer. The powder specimens were exposed to $\mathrm{CuK}_{\alpha}$ radiation with a primary beam of $40 \mathrm{kV}$ and $30 \mathrm{~mA}$ with a sampling pitch of $0.02^{\circ}$ and time for each steps data collection was $1.0 \mathrm{~s}$ to characterize. The microstructures of the samples were done by a scanning electron microscope (SEM) (model: FEI Inspect S50). The SEM micrographs were taken on the smooth surface of the pellet-shaped polished samples. Before taking micrographs, the surface of the samples were thermally etched at a temperature of $150^{\circ} \mathrm{C}$ below the sintering temperature. Frequency dependent complex permeability of the toroid shaped samples at room temperature was measured with 6500B impedance analyzer at frequency range from $1 \mathrm{kHz}$ to $15 \mathrm{MHz}$. The permeability $\mu^{\prime}$ was calculated by $\mu^{\prime}=L / L_{o}$, where $L$ is the measured sample inductance and $L_{0}$ is the air core inductance calculated using the dimensions of the coil. For these measurements an applied voltage of $5 \mathrm{~mA}$ was used with a 5-turn low inductive coil.

\section{Results and Discussion}

The structural study is essential for optimizing the properties needed for various applications. Typical X-ray diffraction pattern (XRD) indicating $(h k l)$ values of each peak corresponding to the sample $x=0.0$ of $\mathrm{Cu}_{1-x} \mathrm{Zn}_{x} \mathrm{Fe}_{2} \mathrm{O}_{4}$ ferrite is illustrated in Fig. 1. XRD

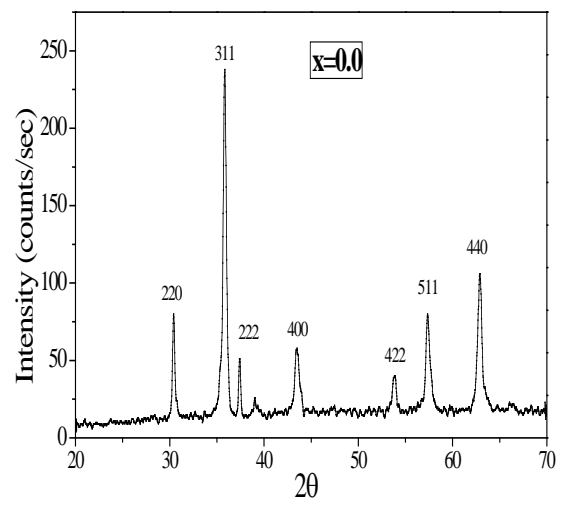

Fig. 1. XRD pattern of $\mathrm{Cu}-\mathrm{Zn}$ ferrite for $x=0.0$.

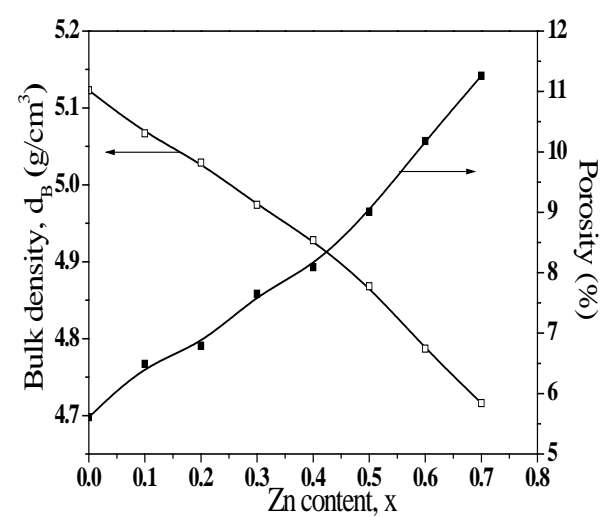

Fig. 2. Bulk density and porosity as a function of $\mathrm{Zn}$ content.

pattern of the ferrite sample, showing well-defined reflections without any ambiguity, exhibited the formation of single-phase cubic spinel structure. Using a standard XRD data the lattice constant and hence X-ray density was determined. The lattice constant was determined through the Nelson-Rilay extrapolation method [11]. The lattice constant was found to increase with increasing $\mathrm{Zn}^{2+}$ ion concentration as given in Table 1 obeying the 
Vegard's law [12]. This increase in lattice constant can be attributed to the ionic size differences since the unit cell has to expand when substituted by ions with large ionic size. Since the ionic radius of $\mathrm{Zn}^{2+}$ ions $\left(R_{\mathrm{Zn}}{ }^{2+}=0.82 \AA\right)$ [13] is larger than that of $\mathrm{Cu}^{2+}$ ions $\left(R_{\mathrm{Cu}}{ }^{2+}=0.73 \AA\right)$ [14], the substitution is expected to increase the lattice constant with the increasing concentration of $\mathrm{Zn}$. It was reported that the value of lattice constant of $\mathrm{CuFe}_{2} \mathrm{O}_{4}$ is $8.380 \AA$ [15]. Our experimental value was $8.365 \AA$, which was almost similar to the reported value. This slight difference in the value of the lattice constant may be due to the different scattering source, different sintering and preparation techniques.

The effect of $\mathrm{Zn}$ ion on bulk density and on the porosity was shown in Table 1 and Fig. 2. A decreasing trend in bulk density and increasing trend in porosity has been observed with the increasing of $\mathrm{Zn}$ content. The decrease of density with $\mathrm{Zn}$ content is expected because of lower density of $\mathrm{ZnFe}_{2} \mathrm{O}_{4}\left(5.33 \mathrm{~g} / \mathrm{cm}^{3}\right)$ [16] as compared to $\mathrm{CuFe}_{2} \mathrm{O}_{4}$ $\left(5.42 \mathrm{~g} / \mathrm{cm}^{3}\right)$ [5]. Moreover this is due to the increase of oxygen vacancies which play a predominant role in accelerating densification i.e. the decrease in oxygen ion (anion) diffusion would retard the densification [17]. Again porosity increase with the addition of $\mathrm{Zn}$ content may be due to the creation of more cation vacancies with the reduction of oxygen vacancies [17]. It was also observed in Table 1 that the bulk density of low sintered temperature (at $950^{\circ} \mathrm{C}$ ) of studied samples was quite higher than that of sintered at $1050^{\circ} \mathrm{C}$. This decrease of density for higher sintering temperature may be attributed to material loss during sintering. Evaporation of $\mathrm{Zn}$ from the samples may result in reduction of $\mathrm{Fe}^{3+}$ ions to $\mathrm{Fe}^{2+}$ and loss of oxygen to maintain charge neutrality in the sample [18]. These results agree with that of earlier reported results in Mg-Cu-Zn ferrite by Qi et al. [19] and in Cu-Zn ferrites by Shahida et al. [20].

Table 1. Experimental results of $\mathrm{Cu}_{1-\mathrm{x}} \mathrm{Zn}_{\mathrm{x}} \mathrm{Fe}_{2} \mathrm{O}_{4}$ ferrites.

\begin{tabular}{|c|c|c|c|c|c|c|c|c|}
\hline $\begin{array}{c}\mathrm{Zn} \\
\text { content } \\
x\end{array}$ & $\begin{array}{c}\text { Lattice } \\
\text { parameter } \\
\quad a(\AA)\end{array}$ & $\begin{array}{c}\text { Bulk density } \\
d_{\mathrm{x}}\left(\mathrm{g} / \mathrm{cm}^{3}\right) \\
T_{\mathrm{s}}=950^{\circ} \mathrm{C}\end{array}$ & $\begin{array}{c}\text { Bulk density } \\
d_{\mathrm{x}}\left(\mathrm{g} / \mathrm{cm}^{3}\right) \\
T_{\mathrm{s}}=1050^{\circ} \mathrm{C}\end{array}$ & $\begin{array}{l}\text { Porosity } \\
\text { (\%) }\end{array}$ & $\begin{array}{l}\text { Grain size } \\
\quad(\mu \mathrm{m}) \\
T_{\mathrm{s}}=950^{\circ} \mathrm{C}\end{array}$ & $\begin{array}{c}\text { Grain size } \\
\quad(\mu \mathrm{m}) \\
T_{\mathrm{s}}=1050^{\circ} \mathrm{C}\end{array}$ & $\begin{array}{c}\mu^{\prime} \text { at } \mathrm{f}=10 \\
\mathrm{kHz} \\
T_{\mathrm{s}}=950^{\circ} \mathrm{C}\end{array}$ & $\begin{array}{c}\mu^{\prime} \text { at } \\
f=10 \mathrm{kHz} \\
T_{\mathrm{s}}=1050^{\circ} \mathrm{C}\end{array}$ \\
\hline 0.0 & 8.3653 & 5.124 & 5.044 & 5.61 & 3.822 & 6.482 & 34.18 & 48.29 \\
\hline 0.1 & 8.3724 & 5.067 & 4.986 & 6.49 & 3.577 & 5.425 & 57.47 & 64.22 \\
\hline 0.2 & 8.3863 & 5.029 & 4.946 & 6.79 & 3.325 & 4.359 & 98.49 & 100.74 \\
\hline 0.3 & 8.3934 & 4.974 & 4.897 & 7.65 & 2.902 & 3.632 & 110.18 & 114.04 \\
\hline 0.4 & 8.4083 & 4.928 & 4.858 & 8.09 & 2.396 & 3.274 & 155.92 & 276.05 \\
\hline 0.5 & 8.4164 & 4.868 & 4.813 & 9.01 & 2.047 & 2.966 & 184.74 & 350.32 \\
\hline 0.6 & 8.4295 & 4.787 & 4.758 & 10.18 & 1.565 & 2.549 & 123.44 & 169.56 \\
\hline 0.7 & 8.4396 & 4.736 & 4.724 & 11.26 & 1.277 & 2.449 & 23.59 & 53.16 \\
\hline
\end{tabular}

Magnetic properties sensitively depend on the microstructure of ferrites. Between the grain size and porosity of microstructures, grain size is more important parameter affecting the magnetic properties of ferrites. The SEM micrographs of $\mathrm{Cu}_{1-\mathrm{x}} \mathrm{Zn}_{\mathrm{x}} \mathrm{Fe}_{2} \mathrm{O}_{4}$ (for $x=0.0,0.4$ and 0.6 ) at $950^{\circ} \mathrm{C}$ and $1050^{\circ} \mathrm{C}$ were illustrated in Fig. 3 and it was seen from the micrographs that the dense microstructures are obtained for all samples. The average 
grain size of the samples calculated using the intercepts method from SEM micrographs has been given in Table 1 . The behaviour of grain growth reflects the competition between the driving force for grain boundary movement and the retarding force exerted by pores [21]. During the sintering, the thermal energy generates a force that drives the grain boundaries to grow over pores, thereby decreasing the pore volume and making the material dense. When the driving force of the grain boundary in each grain is homogeneous,

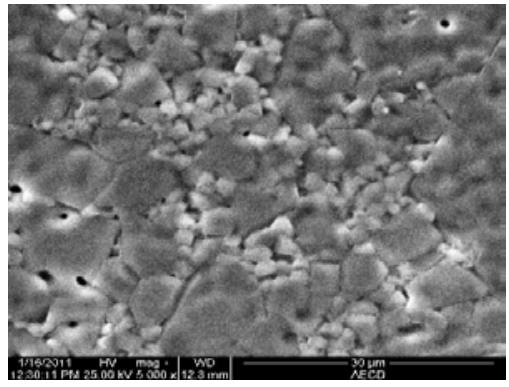

$x=0.0, T_{\mathrm{s}}=950^{\circ} \mathrm{C}$

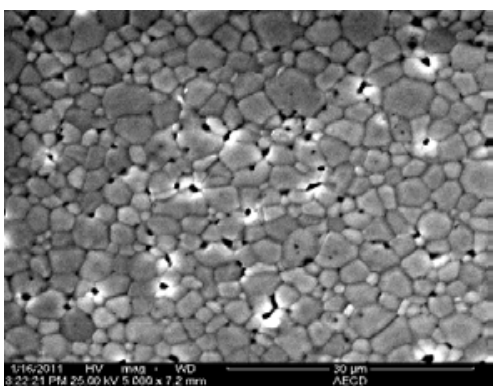

$x=0.2, T_{\mathrm{s}}=950^{\circ} \mathrm{C}$

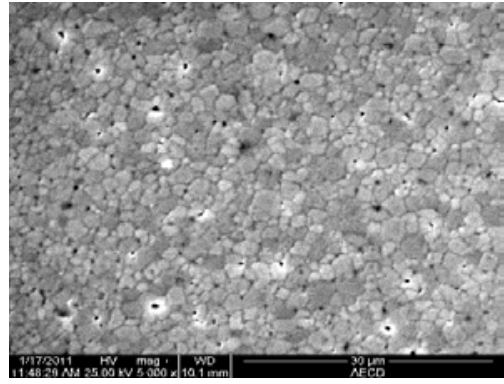

$x=0.5, T_{\mathrm{s}}=950^{\circ} \mathrm{C}$

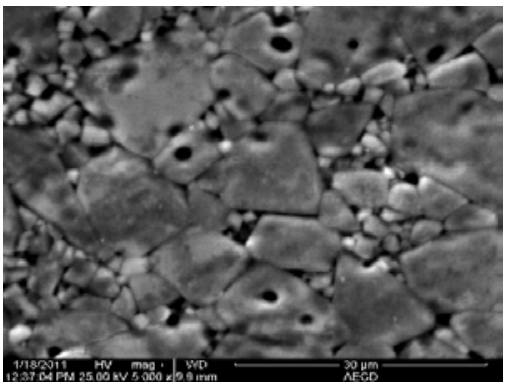

$x=0.0, T_{\mathrm{s}}=1050^{\circ} \mathrm{C}$

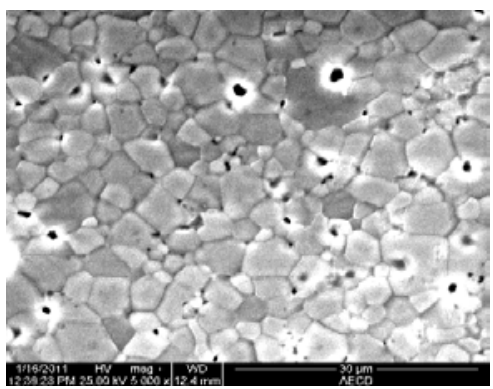

$x=0.2, T_{\mathrm{s}}=1050^{\circ} \mathrm{C}$

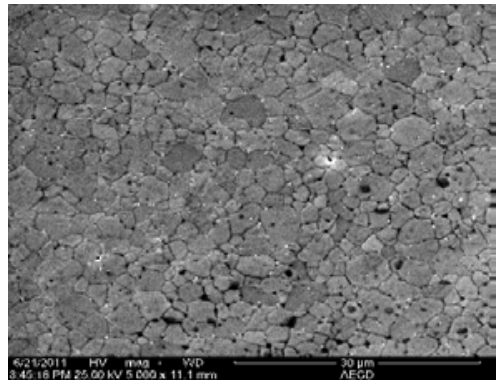

$x=0.5, T_{\mathrm{s}}=1050^{\circ} \mathrm{C}$

Fig. 3. SEM micrographs for $\mathrm{x}=0.0,0.2$ and 0.5 at sintering temperature $950^{\circ} \mathrm{C}$ and $1050^{\circ} \mathrm{C}$.

the sintered body attains a uniform grain size distribution. Moreover, the strength of the driving force depends upon the diffusivity of individual grains, sintering temperature and porosity. Therefore the greater values of grain size for $x=0.0$ could be due to the smaller 
porosity since the pore neutralize the driving force. Grain size decreased due to the reaction condition, which favoured the formation of new nuclei preventing further growth of particles. Hence preparation condition plays an effective role to control the particle size. Preparation condition gives rise to different concentrations of $\mathrm{Zn}$, favouring the variation of particle size. In general, the grain sizes of all samples are smaller than $4 \mu \mathrm{m}$ at $950^{\circ} \mathrm{C}$ which is superior to reduce thickness of each layer in multilayer chip inductors leading to further miniaturization. It is also observed that grain size increased with sintering temperature. This may due to the hindering the migration of the pore to the grain boundary and contributing towards the reduction of the bulk density.

Fig. 4 (a) and 4 (b) show the real part $\left(\mu^{\prime}\right)$ and imaginary part ( $\left.\mu^{\prime \prime}\right)$ of the complex permeability in the range $1 \mathrm{kHz}$ to $15 \mathrm{MHz}$ sintered at $950^{\circ} \mathrm{C}$ and $1050^{\circ} \mathrm{C}$ respectively. From Fig. 4, it is observed that the real permeability, $\mu^{\prime}$ remained almost constant for composition $x=0.0$ to 0.3 up to entire range of frequency (15 MHz). For $x>0.3, \mu^{\prime}$ is observed to be nearly constant over several orders of frequency before it began to decline. The imaginary part $\left(\mu^{\prime \prime}\right)$ also observed rising trend up to a quite broadening peak at a certain frequency where the real part $\left(\mu^{\prime}\right)$ falls to a lower value of permeability. The fairly constant $\mu^{\prime}$ values over a large frequency range show the compositional stability and quality of the ferrites prepared by the solid state reaction. This is a desirable characteristic for various applications such as broadband pulse transformers and wide band read-write heads for video recording. Similar results were observed by Anjali et al. [22] in Ni-Zn ferrite and by Raman et al. [23] in Li-Zn ferrites.
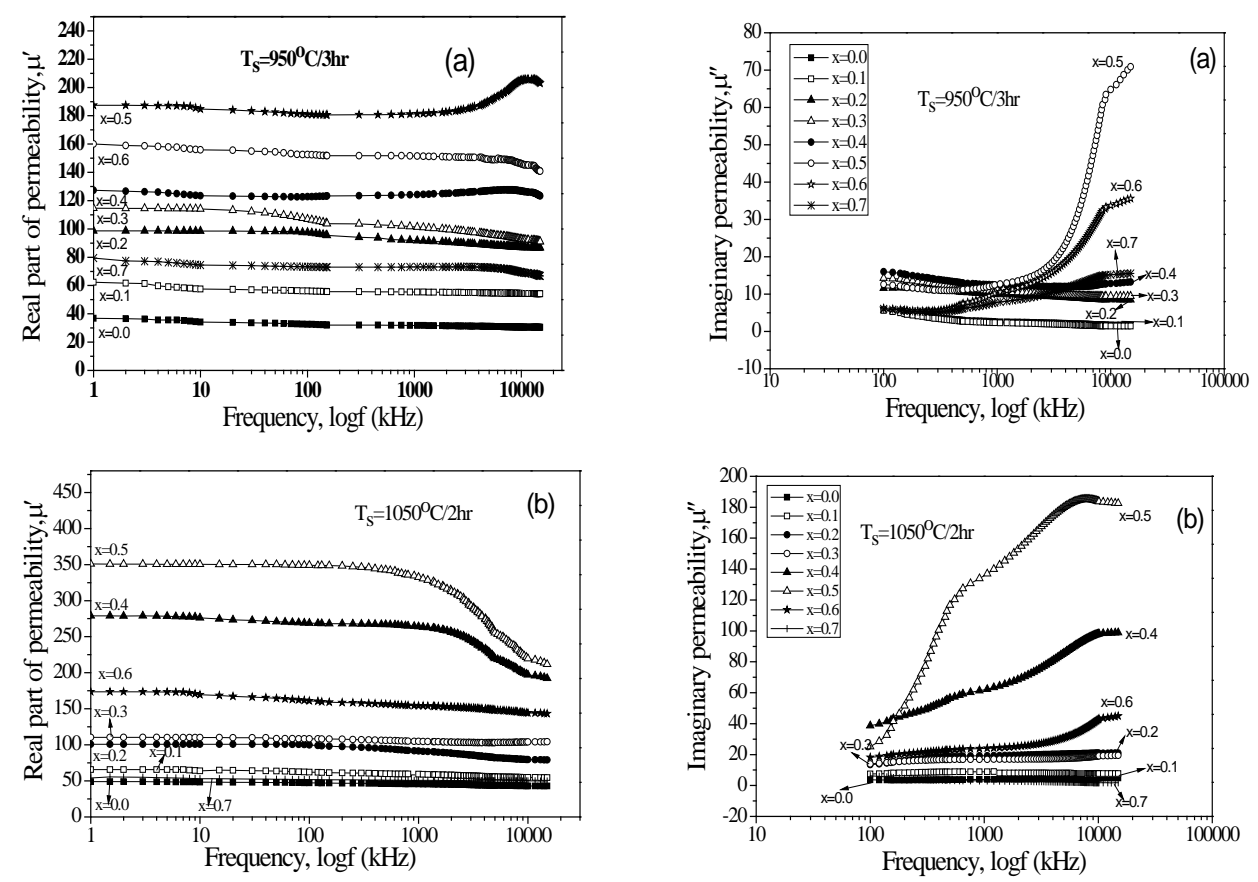

Fig. 4. Frequency dependence of real and imaginary part of permeability at (a) $950^{\circ} \mathrm{C}$ (upper panels) and (b) $1050^{\circ} \mathrm{C}$ (lower panels). 
It was well known that the permeability of polycrystalline ferrite is associated with domain wall relaxation and rotational resonance [24]. Domain wall relaxation is usually observed at lower frequency while the rotational resonance is observed in $\mathrm{MHz}$ frequency range. The imaginary permeability $\left(\mu^{\prime \prime}\right)$ increased with the frequency and reached a maximum at a certain frequency, where the real permeability, $\mu^{\prime}$ starts to decrease. The decrease in permeability implies onset of ferromagnetic resonance [25]. At low frequencies, a ferrite inductor is a low loss constant self-inductor where $\mu^{\prime}$ is highest and the core is mostly inductive, rejecting the electromagnetic interference (EMI) signal to the source. At high frequencies where the $\mu^{\prime \prime}$ parameter becomes more significant, the inductors show high impedance and become resistive and dissipate interfering signals rather than reflecting these to the source. The resonance frequency peaks are the results of the absorption of energy due to matching of the oscillation frequency of the magnetic dipoles and the applied frequency. At the resonance, maximum energy is transferred from the applied field to the lattice in the rapid increase in $\tan \delta\left(\tan \delta=\mu^{\prime \prime} / \mu^{\prime}\right)$. This indicates that lower the permeability values, the higher the frequencies at which resonance phenomenon occurs.

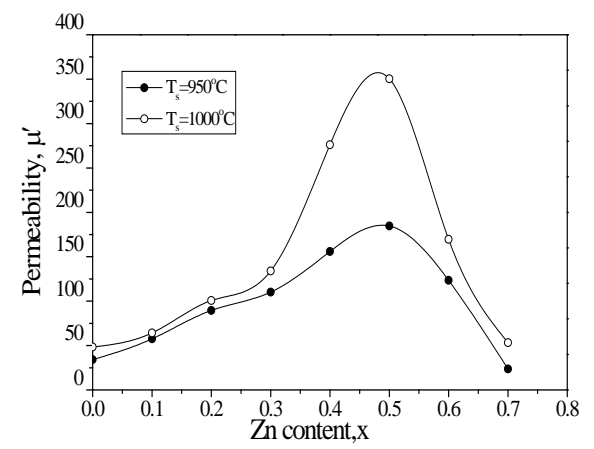

Fig. 5. Variation of permeability with Zn content at $f=10 \mathrm{kHz}$.

Fig. 5 displays the variation of initial permeability with composition at $950^{\circ} \mathrm{C}$ and $1050^{\circ} \mathrm{C}$. Permeability was found to increase with the increase of Zn content up to $x=0.5$ and thereafter decrease. According to Globus equation [26], the permeability due to the wall motion is likely to be linearly dependent on the grain size which is given by

$$
\mu_{i} \propto \frac{M_{s}^{2} D}{\sqrt{K_{1}}}
$$

where $M_{\mathrm{s}}$ is the saturation magnetization; $D$ is the average grain size, $K_{1}$ is the anisotropy constant. It is generally known that the larger grain sizes, the higher the saturation magnetization and initial permeability. However, the variation of initial permeability with Zn content was not consistent with the variation of microstructures, the bulk density and 
the above empirical principle. This phenomenon might be explained by the following equation:

$$
\mp x \frac{M_{s}^{2}}{a K_{1}+b \sigma}
$$

where $\mu_{\mathrm{i}}$ is the initial permeability, $M_{\mathrm{s}}$ is the saturation magnetization, $K_{1}$ is the crystal anisotropy constant, $\lambda$ is the magnetostriction constant, $\sigma$ is the inner stress, and $a, b$ are two constants. According to Nam et al. [27] Mn substitution within small range in composition plays a crucial role in the properties of NiCuZn ferrites by reducing magnetostriction effects. Therefore with the increase of $\mathrm{Zn}$ content, the increase of the initial permeability of CuZn ferrites was attributed to the decrease of magnetostriction constant. The same conclusions have been confirmed by investigations by Nakano [28] and Qi [19]. From microstructures we could see that the grain sizes tended to become smaller and the distributions of pores were more even which might help to diminish inner stress and lead to an increase of initial permeability. In comparison with the reported results of NiCuZn ferrites prepared by the same method, low temperature sintered CuZn ferrites possess higher initial permeability and better grain structure. The higher initial permeability, low cost, low sintering temperature and smaller grain size characteristics make the $\mathrm{Zn}$ substituted CuZn ferrites be the most potential candidate material for Multilayer chip inductor (MLCI) industry. It is also observed from Fig. 5 that permeability increases with sintering temperature. The increase in the sintering temperature results in a decrease in the magnetic anisotropy by decreasing the internal stress and crystal anisotropy which reduce the hindrance to the movement of the domain walls resulting thereby in the value of $\mu^{\prime}$ [29-31].

\section{Conclusions}

Mixed Cu-Zn ferrites of various compositions are synthesized by standard ceramic technique sintered at different temperature. The XRD pattern shows the formation of single phase cubic structure for all the samples. The lattice parameters of $\mathrm{Cu}-\mathrm{Zn}$ ferrite increase when $\mathrm{Cu}$ is substituted by divalent ion of $\mathrm{Zn}^{2+}$. With the increase of $\mathrm{Zn}$ content the sintered density and the grain size decreased whereas an increase is found in porosity. The increase in initial permeability of $\mathrm{Cu}-\mathrm{Zn}$ ferrite with the $\mathrm{Zn}$ content were attributed to the presence of $\mathrm{Zn}$ ions activating the sintering process in ferrites and leading to decrease in density and grain size. Under the above investigation it is concluded that the higher initial permeability, lower sintering temperature and smaller grain size characteristics make the Zn substituted $\mathrm{Cu}-\mathrm{Zn}$ ferrites potential candidate materials for multilayer chip inductor (MLCI) industry.

\section{Acknowledgements}

The author (Shahida Akhter) gratefully acknowledges the 'Bangabandhu Fellowship on Science, Information and Technology' Fund of the People’s Republic of Bangladesh for 
granting her a Ph.D. fellowship for carrying out this work. She is also grateful to Materials Science Division of Atomic Energy Centre, Dhaka (AECD) for allowing her prepare the samples and to utilize its laboratory facilities.

\section{References}

1. N. Reslescu, E. Reslescu, C. L. Sava, F. Tudorache, and P. D. Popa, Crystal Res. Tech. 39 (6), 548 (2004). http://dx.doi.org/10.1002/crat.200310223

2. S. A. Patil, S. M. Otari, N. C. Mahajan, M. G. Patil, A. B. Patil, and M. K. Soandogar, Solid State Commun. 78 (1), 39 (1991). http://dx.doi.org/10.1016/0038-1098(91)90805-6

3. E. E. Riches, 'A Review of Materials and Applications', J. G. Cook (ed.) (Mills and Boon, London, 1972) p. 17.

4. A. J. Ali, J. Rahman, and M. A. Chowdhury, Jpn. J. Appl. Phys. 39, 3378 (2000). http://dx.doi.org/10.1143/JJAP.39.3378

5. M. Hoque, M. A. Chowdhury, and M. F. Islam, J. Magn. Magn. Mater. 251, 292 (2002). http://dx.doi.org/10.1016/S0304-8853(02)00700-X

6. H. Shokrollahi and K. Janghorban, Mater. Sci. Eng. B 141, 91 (2007). http://dx.doi.org/10.1016/j.mseb.2007.06.005

7. G. T. Rado, Rev. Mod. Phys. 25, 81(1953). http://dx.doi.org/10.1103/RevModPhys.25.81

8. J. Smit and H. M. J. Wijn, Ferrites (Philips Technical Library Eindhoven, The Netherland, 1959).

9. E. Scloemann, J. Appl. Phys. 41, 204(1970). http://dx.doi.org/10.1063/1.1658322

10. J. P. Bouchaud and P. G. Zerah, J. Appl. Phys. 67, 5512 (1990). http://dx.doi.org/10.1063/1.345868

11. J. B. Nelson and D. P. Riley, Proc. Phys. Soc. London 57, 160 (1945). http://dx.doi.org/10.1088/0959-5309/57/3/302

12. L. Vegard, Physics and Astronomy 5, 17 (1921).

13. J. Smit and H. M. J. Wijn, Ferrites (Wiley New York, 1959) p.143.

14. D. N. Bhosale, N. D. Choudhari, S. R. Sawant and P. P. Bakare, J. Magn. Magn. Mater. 173, 51 (1997). http://dx.doi.org/10.1016/S0304-8853(97)00178-9

15. I. P. Parkin, G. E. Eluin, A. V. Komarov, Q. T. Bui, and Q. A. Pankhurst, Adv. Matter 9, 642 (1997). http://dx.doi.org/10.1002/adma.19970090811

16. J. M. Hanting and L.M. Corliss, Rev. Mod. Phys. 25, 114 (1953). http://dx.doi.org/10.1103/RevModPhys.25.114

17. T. Abbas, M. U. Islam, and M. A. Choudhury, Mod. Phy. Letts. B 9 (22), 1419 (1995). http://dx.doi.org/10.1142/S0217984995001418

18. A. Verma, O. P. Thakur, C. Prakash, T. C. Goel, and R. G. Mendirth, J. Mater. Sci. Eng. B 116, 1 (2005). http://dx.doi.org/10.1016/j.mseb.2004.08.011

19. Q. Xiwei, J. Zhou, Y. Zhenxing, G. Zhilun, and L. Longtu, J. Magn. Magn. Mater. 251, 316 (2002). http://dx.doi.org/10.1016/S0304-8853(02)00854-5

20. S. Akhter, D. P. Paul, M. A. Hakim, D. K. Saha, M. Al Mamun, and A. Parveen, J. Mater. Sci. Applic. 2, 1675 (2011).

21. S. S. Bellad, S. C. Watawe, and B. K. Chougule, J. Magn. Magn. Mater. 195, 57 (1999). http://dx.doi.org/10.1016/S0304-8853(98)01073-7

22. A. Verma and R. Chatterjee, J. Magn. Magn. Mater. 306, 313 (2006). http://dx.doi.org/10.1016/j.jmmm.2006.03.033

23. R. Raman, V. R. K. Murthy, and B. Viswanathan, J. Magn. Magn. Mater. 102, 181 (1991). http://dx.doi.org/10.1016/0304-8853(91)90285-I

24. T. Tsutaoka, M. Ueshima, T. Tokunaga, T. Nakamura, K. Hatakeyama, J. Appl. Phys. 78(6), 3983 (1995). http://dx.doi.org/10.1063/1.359919

25. F. G. Brockman, P. H. Dowling, and W. G. Steneck, J. Phys. Rev. 77, 85 (1950). http://dx.doi.org/10.1103/PhysRev.77.85 


\section{Microstructure and Complex Permeability}

26. A. Globus and P. Duplex, IEEE Trans. Magn. MAG-2, 441 (1966). http://dx.doi.org/10.1109/TMAG.1966.1065867

27. J. H. Nam, J. H. Oh and W. G. Hur, J. Appl. Phys. 81 (8), 4795 (1997). http://dx.doi.org/10.1063/1.365466

28. A. Nakano, T. Nomura, and T. Murse, J. Jpn. Soc. Powder Powder Metall. 48 (2), 131 (2001). http://dx.doi.org/10.2497/jispm.48.131

29. A. Verma and T. C. Goel, J. Magn. Magn. Mater. 210, 274 (2000). http://dx.doi.org/10.1016/S0304-8853(99)00451-5

30. K. H. Maria, S. Choudhury, and M. A. Hakim, J. Bangl. Acad. Sci. 34 (1), 1 (2012).

31. M. M. Rahman, P. K. Halder, F. Ahmed, T. Hossain, and M. Rahaman, J. Sci. Res. 4 (2), 297 (2012). http://dx.doi.org/10.3329/jsr.v4i2.9752 